\title{
Increasing Distribution Network Capacity using Automation to Reduce Carbon Impact
}

\author{
S M Blair*, C D Booth*, P Turner ${ }^{\dagger}$, V Turnham ${ }^{\dagger}$ \\ *University of Strathclyde, UK, steven.m.blair@strath.ac.uk, ${ }^{\dagger}$ Electricity North West Limited, UK, paul.turner@enwl.co.uk
}

Keywords: Automation, demand-side response, distribution systems, interconnection.

\begin{abstract}
Distribution networks must be equipped for a significant increase in future electrical demand. This challenge must be met in a cost-effective manner and without undue environmental impact. This paper quantifies the operational benefits of the Capacity to Customers $\left(\mathrm{C}_{2} \mathrm{C}\right)$ project presently being led by Electricity North West Limited in the UK. The objective of the project is to use demand-side response (DSR) technology and increased network interconnection to significantly increase the available network capacity, avoiding the cost and environmental impact of traditional reinforcement.

Through the analysis of real distribution circuit data for a cross-section of circuits involved in the project trial, and assuming evenly-distributed load growth, it is shown that the presence of DSR increases usable circuit capacity by a mean of $66 \%$. The use of network interconnection generally reduces the number of steady-state voltage constraints and thereby yields a further increase in capacity. Consequently, it is shown that interconnection significantly reduces the need for cable and overhead line reinforcement, often needed for connecting relatively large industrial and commercial loads. The paper also comments on protection issues that could potentially impact upon $\mathrm{C}_{2} \mathrm{C}$ deployment.
\end{abstract}

\section{Introduction}

Distribution networks must be equipped for a significant increase in future electrical demand, due to the continuing electrification of transport and heating [1]. This challenge must be met in a cost-effective manner and without undue environmental impact. It is also important that this can be delivered without compromising network protection or the security of supply.

This paper quantifies several technical aspects of the Capacity to Customers $\left(\mathrm{C}_{2} \mathrm{C}\right)$ project [2], a Low Carbon Network Fund [3] project presently being led by Electricity North West Limited (ENWL) in conjunction with several industrial and academic partners. $\mathrm{C}_{2} \mathrm{C}$ aims to test a combination of new automation technology, unconventional network operational practices (i.e., increased network interconnection), and commercial demand-side response (DSR) contracts. These changes will allow the network operator to increase the loadings on a selection of trial circuits-representing approximately $10 \%$ of its $6.6 / 11$ $\mathrm{kV}$ network-without resorting to conventional reinforcement measures. The project will thereby "release" inherent spare capacity in the $6.6 / 11 \mathrm{kV}$ system in order to accommodate the future forecast increases in demand, whilst avoiding (or deferring) the cost and environmental impacts that are associated with traditional network reinforcement.

The paper focuses on the analysis of the effects of $\mathrm{C}_{2} \mathrm{C}$ operation on available network capacity, the network reinforcement required for increased demand, fault levels, and the associated protection issues, building on the results presented in [4]. This has been achieved using IPSA [5] simulation models incorporating real system data for a representative proportion of the $\mathrm{C}_{2} \mathrm{C}$ trial circuits.

\section{$2 \mathrm{C}_{2} \mathrm{C}$ Project Overview}

$\mathrm{C}_{2} \mathrm{C}$ is possible due to DSR contracts with managed customers, combined with derogation from the conventional recommendations for security of supply in distribution networks in the UK, governed by Engineering Recommendation (ER) P2/6 [6]. During line outages following faults, managed customers may be completely or partially disconnected (i.e., their load is managed) due to the temporary reduction in available capacity. In exchange, new customers are offered attractive connection contracts and existing customers are offered monthly payments, such that they are financially compensated when their connection is managed; the costs to the network operator being met from the benefits accrued from avoidance of network reinforcement.

Figures 1-3 provide a simplified overview of the aims of $\mathrm{C}_{2} \mathrm{C}$. Spare thermal capacity-normally reserved for use during circuit outages-will be offered to new customers. By closing normally-open points (NOPs), additional loads, with managed contracts for post-fault conditions, can be connected by using the thermal capacity available from both radial feeders. As depicted in Figure 2, by closing the NOP, it is also possible to connect a single large load using the spare capacity from both radial feeders (where, in this example, each feeder has a maximum thermal capacity for 6 MVA of load). Network automation is important for ensuring correct and timely restoration of customers after faults, and for managing the available capacity. 


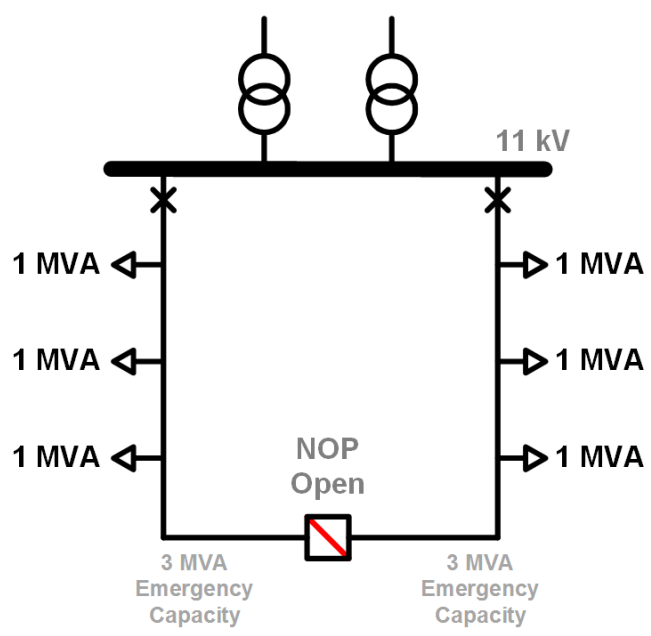

Figure 1: Conventional radial operation, with no usable spare capacity (emergency capacity not presently offered to customers)

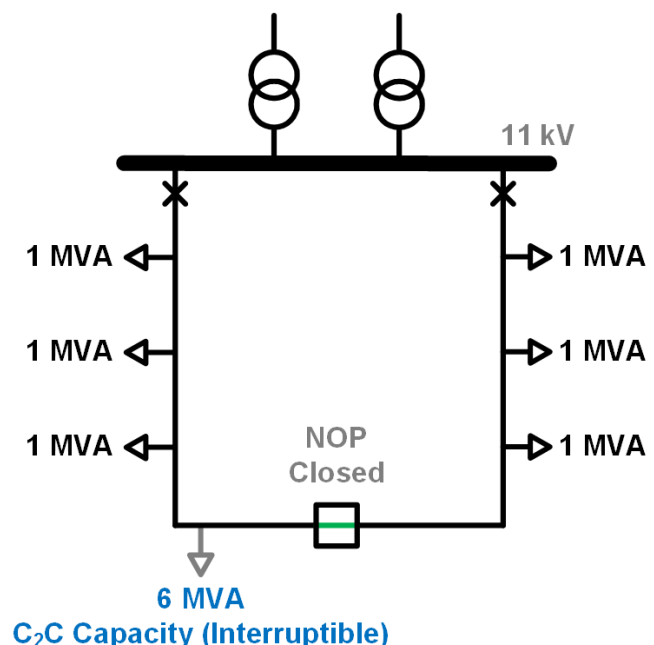

Figure 2: $\mathrm{C}_{2} \mathrm{C}$ operation, with additional capacity for interruptible loads (large, single load)

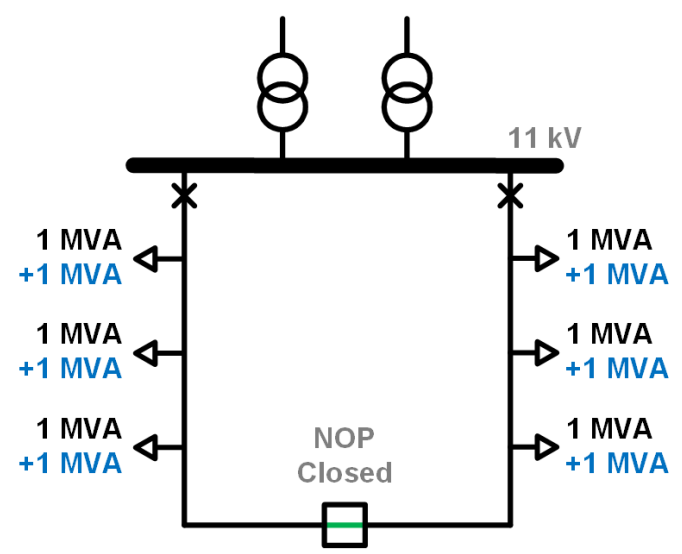

Figure 3: $\mathrm{C}_{2} \mathrm{C}$ operation, with additional capacity for interruptible loads (distributed load growth)

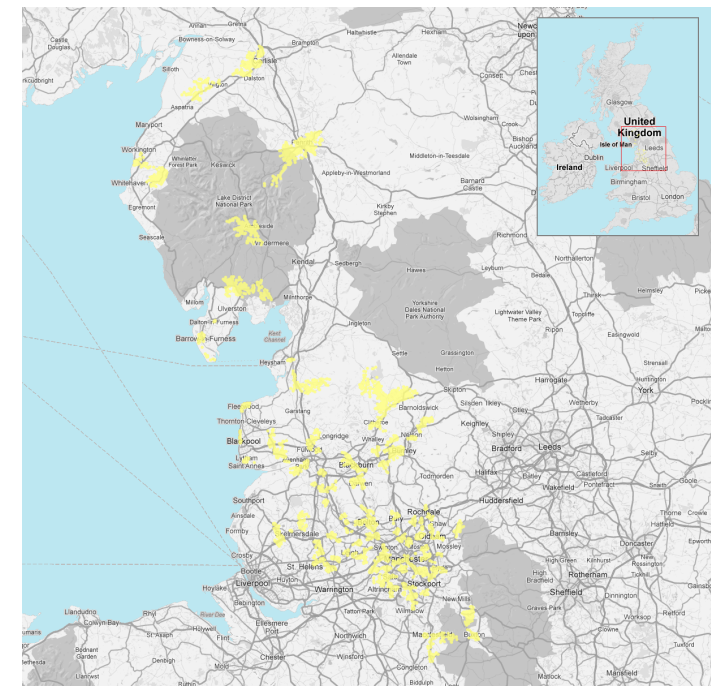

Figure 4: Map of $\mathrm{C}_{2} \mathrm{C}$ trial locations highlighted in yellow, from [7] (Map data 2013 GeoBasis-DE/BKG (2009), Google)

A field trial of $\mathrm{C}_{2} \mathrm{C}$ operation is presently underway, involving 180 ring circuits throughout the Electricity North West network, as shown in Figure 4. These circuits have been selected due to their relatively low historical rates of fault occurrence, and to ensure that excessive fault levels are not introduced by closing NOPs; these practical conditions would also be applicable if the $\mathrm{C}_{2} \mathrm{C}$ method is offered beyond the trial period. From the 180 trial circuits, 36 circuits have been selected for detailed monitoring and analysis.

\section{Effect of $\mathrm{C}_{2} \mathrm{C}$ on Capacity}

The potential capacity available by adopting $\mathrm{C}_{2} \mathrm{C}$ operation has been determined from the maximum possible additional interruptible load which can be connected, assuming that the load growth is distributed evenly throughout each ring circuit. Initially, each circuit is loaded to the conventional (i.e., according to ER P2/6) firm capacity for non-interruptible loads. For each circuit, the load is increased until either:

1. A cable or line thermal headroom (i.e., the remaining thermal capacity) constraint is reached, or

2. A steady-state bus voltage constraint is reached (voltage less than $94 \%$ nominal voltage).

The results are provided in Figure 5. Approximately $80 \%$ of circuits are limited by a thermal constraint rather than a voltage constraint, as given in Table 1. For interconnected operation, a mean increase in loading of $74 \%$ (across all circuits) is possible, compared with $66 \%$ for radial operation; this can be attributed to the reduced occurrence of voltage constraints as given in Table 1. Clearly, the use of DSR is the dominating 


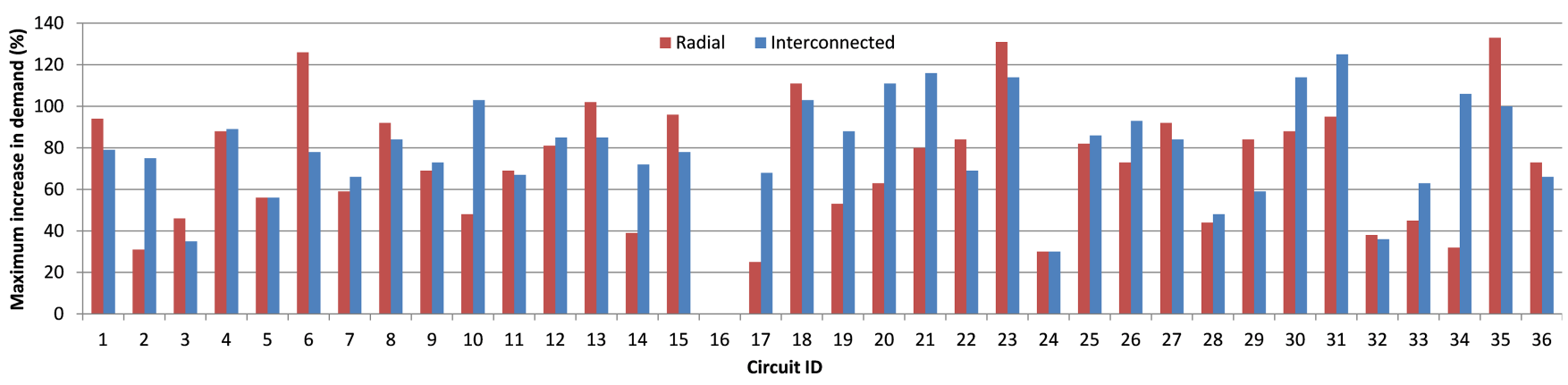

Figure 5: Potential increase in circuit capacity resulting from $\mathrm{C}_{2} \mathrm{C}$ operation

factor for permitting load growth, rather than increased interconnection. For circuit 16 in Figure 5, which is a rural network with a significant presence of relatively long overhead lines, the system presently operates close to the voltage limit and there is no prospect for directly adding any interruptible load (without also implementing other measures to support the network voltage).

\begin{tabular}{|l|l|l|}
\hline & $\begin{array}{l}\text { Radial } \\
\text { operation }\end{array}$ & $\begin{array}{l}\text { Interconnected } \\
\text { operation }\end{array}$ \\
\hline $\begin{array}{l}\text { Voltage } \\
\text { constraints }\end{array}$ & $22 \%$ & $17 \%$ \\
\hline $\begin{array}{l}\text { Thermal } \\
\text { constraints }\end{array}$ & $78 \%$ & $83 \%$ \\
\hline
\end{tabular}

Table 1: Comparison of circuit constraint types

These results highlight that there is significant variation in the available capacity across all circuits because the capacity depends on the circuit topology and the load distribution. For example, a circuit which is relatively heavily loaded at the "extremes" of each radial feeder (e.g., near the NOP) would be expected to benefit the most from interconnected operation.

Applying $\mathrm{C}_{2} \mathrm{C}$ operation to a circuit would be expected to reduce electrical losses due to the increased interconnection [4]. It is important to note that this benefit would diminish over time as the demand on the circuit grows; for heavily-loaded circuits the electrical losses would be higher compared with adopting traditional reinforcement. Figure 6 and Figure 7 illustrate the total circuit losses for conventional operation (i.e., firm capacity with only non-interruptible demand, shown in Figure 1) and for $\mathrm{C}_{2} \mathrm{C}$ operation (with the maximum additional interruptible demand, shown in Figure 3), respectively. Note that different loadings are present for radial and interconnected operation in each case.

\section{Effect of $\mathrm{C}_{2} \mathrm{C}$ on Future Reinforcement}

The effect of $\mathrm{C}_{2} \mathrm{C}$ operation on the need for future network reinforcement has been assessed by simulating an additional point load on each ring circuit, as illustrated in Figure 2. Several locations on each ring circuit and a range of load ratings which are typical of relatively large industrial or commercial customers ( 0.5 to $4 \mathrm{MVA}$ ) have been tested. The radial firm capacity has been used as the base loading. From a total of 2916 scenarios, 697 require reinforcement due to a thermal or voltage constraint introduced by the additional point load (typically loads rated at 3 MVA or higher). For thermal constraints, the appropriate reinforcement action is applied to the simulation model, i.e., overlaying the constrained cable section (typically the first section of a radial feeder) with a higher-rated conductor.

In $74 \%$ of 697 cases requiring reinforcement for radial operation, interconnected operation avoids the need for reinforcement. In a further $22 \%$ of cases, interconnected operation reduces the number of sections requiring reinforcement. The remaining $4 \%$ of scenarios require the same extent of reinforcement for both radial and interconnected operation. These results highlight the potential for significant cost savings and associated reduction in carbon emissions which can result from interconnected operation. Further work by the project partners will evaluate the overall impact of $\mathrm{C}_{2} \mathrm{C}$ operation on cost and carbon emissions, considering electrical losses, transformer replacement, and other factors.

\section{Protection Issues}

\subsection{Protection Settings}

Increased interconnection can lead to disadvantages such as higher fault levels and the requirement for unit protection [8]. $\mathrm{C}_{2} \mathrm{C}$ would not be recommended for circuits which are likely to experience these issues. For the duration of the $\mathrm{C}_{2} \mathrm{C}$ trial, it has been necessary to use the existing protection settings (designed for radial operation), because the system will be operated in both interconnected and radial modes. It was not practical to dynamically update protection setting groups, within the scope of the project. To date, five faults have occurred on trial circuits and the protection and automation schemes operated correctly [9].

The typical protection policy for 6.6/11 kV feeders in ENWL's network is to use standard inverse phase overcurrent and earth fault protection, with a maximum clearance time of $1 \mathrm{~s}$ for 


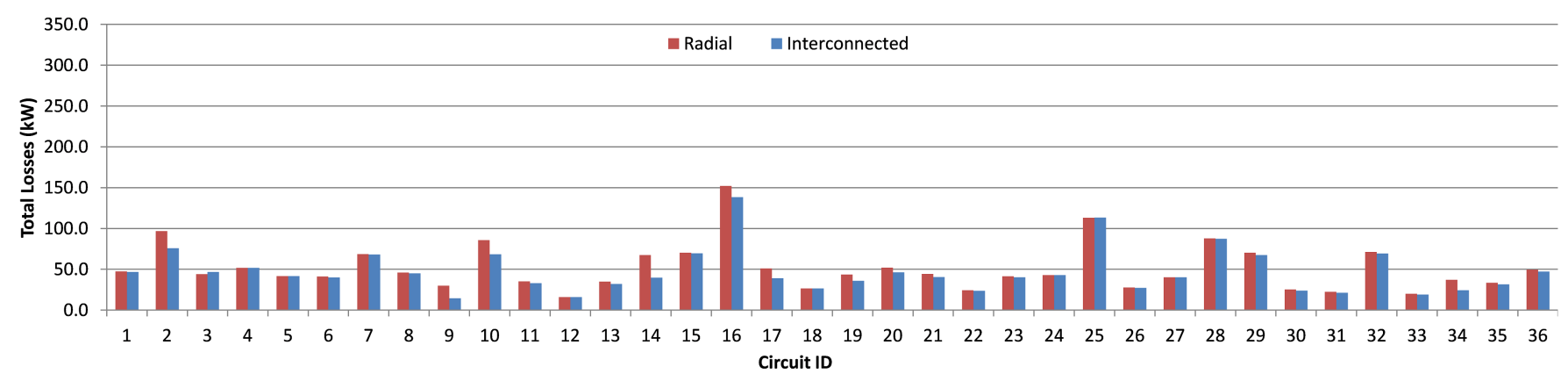

Figure 6: Total circuit losses for conventional operation (firm capacity with only non-interruptible demand)

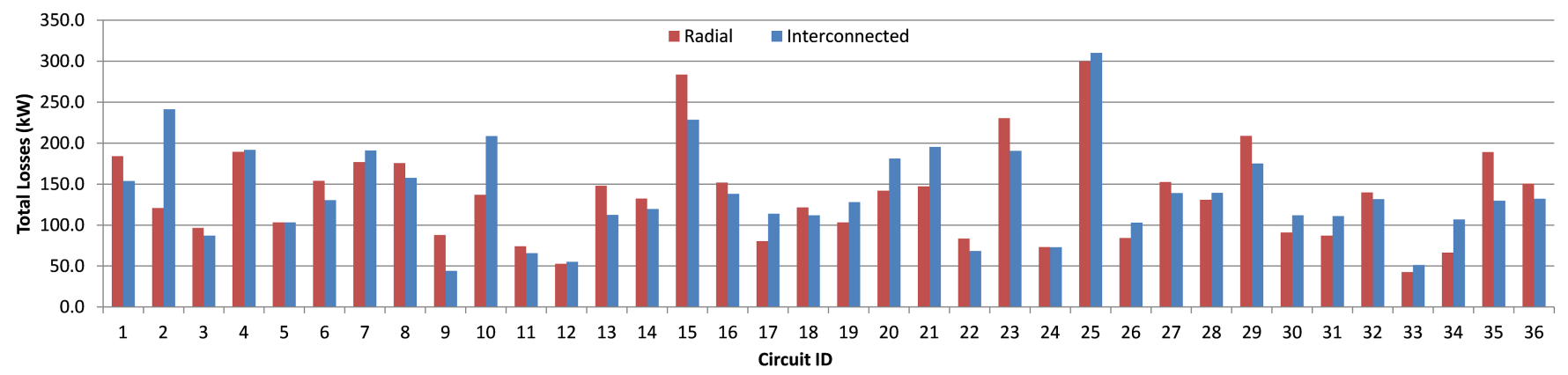

Figure 7: Total circuit losses for $\mathrm{C}_{2} \mathrm{C}$ operation (with the maximum additional interruptible demand)

$6.6 / 11 \mathrm{kV}$ faults near a primary $33 / 11 \mathrm{kV}$ (or 33/6.6 kV) substation [10]. Sensitive earth fault (SEF) protection is typically used for relatively long overhead lines. Directional overcurrent protection and unit protection are only used in exceptional circumstances. During the $\mathrm{C}_{2} \mathrm{C}$ trial, closed rings will not be created from feeders from different primary substations [11], to avoid issues with SEF protection maloperation during switching events, i.e., when closing rings.

\subsection{Fault Level Analysis}

Increased system interconnection increases fault levels due to the lower system impedance. Figure 8 illustrates the increase in fault level for three-phase faults, located the near the NOP on each radial feeder, for interconnected operation. These locations would typically experience the greatest change in fault level due to interconnected operation. The mean increase is $39 \%$. Similarly, Figure 9 illustrates the increase in single-phase to earth fault level, with a mean increase of $31 \%$. There is significant variation in the results due to the relative location of the NOP in each ring circuit and the consequent differences in feeder impedance due to the length of the conductors in the fault current path.

It should be noted that these fault level results represent the fault current at the point of fault, which will be supplied by two paths as opposed to one. The fault current flowing along each feeder will not increase, and therefore there should be no increase in the risk of damage to plant carrying fault current as a consequence of operating closed rings.
These results assume a base fault level at the primary 33/11 $\mathrm{kV}$ (or $33 / 6.6 \mathrm{kV}$ ) substations of $250 \mathrm{MVA}$ and an $X / R$ ratio of 20 [12]. Although the actual fault level and $X / R$ ratio will differ for each circuit (and may vary over time), this provides a consistent base for comparison. The fault contribution from distributed generation is not included, and a fault impedance of zero is assumed. The estimated fault loop impedance is included in the zero-sequence impedance values from conductor data sheets $[13,14]$.

\subsection{Busbar Splitting Schemes}

Primary 33/11 kV (or 33/6.6 kV) substations typically use a busbar splitting scheme to help maximise security of supply if main feeder protection fails to operate after a time delay, or following circuit breaker failure [10]. An example of such a scheme is illustrated in Figure 10 for a feeder earth fault, for a substation without relatively modern protection relays. The first-stage standby earth fault (SBEF) protection will trip the busbar circuit breaker and the appropriate circuit breakers for outgoing feeders of any closed rings. This prevents healthy parts of the system, including the ring circuit, from supplying fault current.

Due to the presence of managed load on $\mathrm{C}_{2} \mathrm{C}$ ring circuits, the first-stage SBEF scheme must be disabled unless automation is present to ensure that $\mathrm{C}_{2} \mathrm{C}$ circuits are not overloaded; otherwise there is a risk of needing to isolate the entire substation. This is an example of the protection issues which must be considered if wider implementation of $\mathrm{C}_{2} \mathrm{C}$, which relies upon DSR, is to be adopted in the future. 


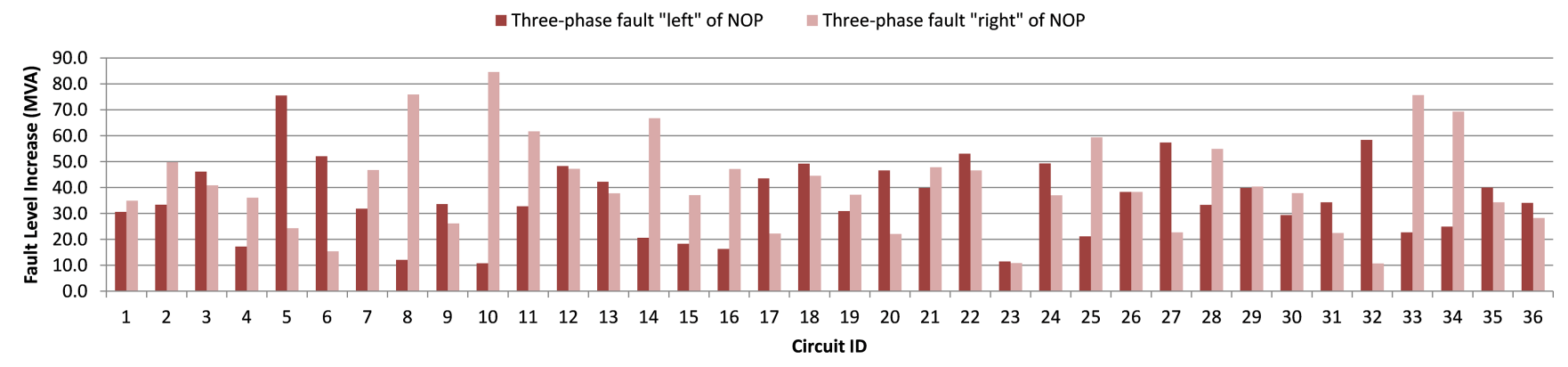

Figure 8: Increase in three-phase fault level for interconnected vs. radial operation

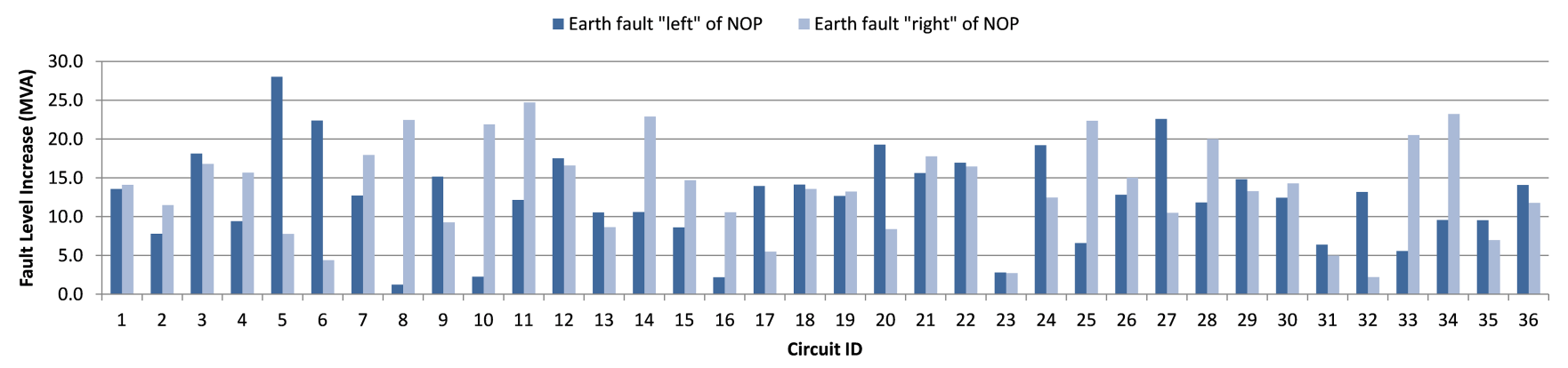

Figure 9: Increase in single-phase to earth fault level for interconnected vs. radial operation

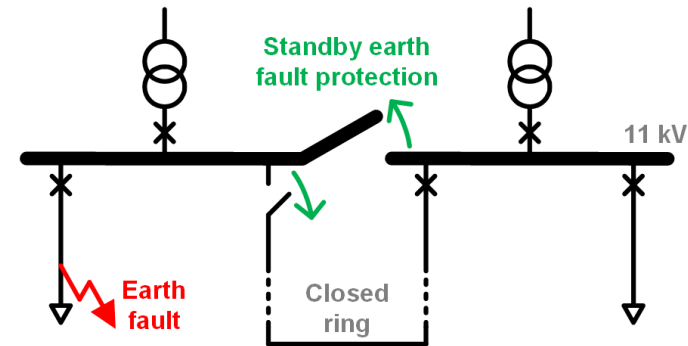

Figure 10: Example of first-stage SBEF tripping

\section{Conclusions and Further Work}

The results arising from the analyses of several circuits show that there generally are benefits from increased interconnection. By allowing the connection of interruptible loads, the available capacity for distributed load is significantly increased, by approximately $66 \%$, assuming evenly-distributed load growth. Interconnected operation generally yields a further improvement in the available capacity, as well as potentially permitting the use of spare capacity from both radial feeders. Consequently, interconnected operation can significantly reduce the need for network reinforcement. For heavilyloaded circuits, these benefits come at the expense of higher electrical losses compared with traditional reinforcement.

Further work will analyse the impact of $\mathrm{C}_{2} \mathrm{C}$ operation when connecting distributed generation. The effects of $\mathrm{C}_{2} \mathrm{C}$ operation on power quality will be evaluated, using data captured from extensive power quality monitoring during the trial. The economic benefits and a detailed assessment of the carbon impact of $\mathrm{C}_{2} \mathrm{C}$ operation will also be conducted by the project partners.

\section{References}

[1] J. Lassila, V. Tikka, J. Haakana, and J. Partanen, "Electric cars as part of electricity distribution - who pays, who benefits?" IET Electrical Systems in Transportation, vol. 2, no. 4, p. 186, 2012.

[2] Electricity North West Ltd., "Electricity North West Capacity to Customers (C2C) project," 2013. [Online]. Available: http://www.enwl.co.uk/c2c

[3] Ofgem, "Low Carbon Networks Fund," 2014. [Online]. Available: https://www.ofgem.gov.uk/electricity/distributionnetworks/network-innovation/low-carbon-networksfund

[4] S. M. Blair, C. D. Booth, P. Turner, and V. Turnham, "Analysis and Quantification of the Benefits of Interconnected Distribution System Operation," in Advanced Power System Automation and Protection (APAP), Jeju, South Korea, 2013.

[5] TNEI Services Ltd, "IPSA Power," 2013. [Online]. Available: http://www.ipsa-power.com/

[6] ENA, "Engineering Recommendation P2/6 - Security of Supply," Tech. Rep., 2006. 
[7] Electricity North West Ltd, "C2C - Postcode search," 2013. [Online]. Available: $\quad$ http://www.enwl.co.uk/c2c/are-youaffected/postcode-search

[8] Scottish Power MANWEB, "Long Term Development Statement,” SP MANWEB plc, Tech. Rep., 2007.

[9] Electricity North West Ltd, "Fault Restoration Performance on $\mathrm{HV}$ rings as part of the Capacity to Customers Project," Electricity North West Ltd, Tech. Rep., 2013. [Online]. Available: http://www.enwl.co.uk/docs/default-source/c2c-keydocuments/white-paper-fault-performance-of-hvrings.pdf?sfvrsn $=6$

[10] Electricity North West Ltd, "Electricity Policy Document 350: Protection for $132 \mathrm{kV}, 33 \mathrm{kV}$ and $11 / 6.6 \mathrm{kV}$ Systems," Electricity North West Ltd, Tech. Rep., 2011.

[11] G. E. Williamson and P. Turner, "Trial Circuit Selection Methodology," Electricity North West Ltd, Tech. Rep., 2012. [Online]. Available: http://www.enwl.co.uk/docs/defaultsource/c2c-key-documents/trial-circuit-selectionmethodology1F73D00A0AD1.pdf?sfvrsn=10

[12] Electricity North West Ltd, "Code of Practice 204: Network Component Impedance Data," Electricity North West Ltd, Tech. Rep., 2010.

[13] Electricity North West Ltd, "Code of Practice 206: Current Ratings of Overhead Line Conductors," Electricity North West Ltd, Tech. Rep., 2008.

[14] Electricity North West Ltd, "Code of Practice 203: Current Ratings - Underground Cables,” Electricity North West Ltd, Tech. Rep., 2009. 